\title{
The 2007 Nazko, British Columbia, Earthquake Sequence: Injection of Magma Deep in the Crust beneath the Anahim Volcanic Belt
}

\author{
J.F. Cassidy \\ N. Balfour \\ C. Hickson \\ H. Kao \\ R. White
}

See next page for additional authors

Follow this and additional works at: https://cedar.wwu.edu/geology_facpubs

Part of the Geology Commons, and the Volcanology Commons

\section{Recommended Citation}

Cassidy, J. F.; Balfour, N.; Hickson, C.; Kao, H.; White, R.; Caplan-Auerbach, Jacqueline; Mazzotti, S.; Rogers, G. C.; Al-Khoubbi, I.; Bird, A. L.; Esteban, L.; Kelman, M.; Hutchinson, J.; and McCormack, D., "The 2007 Nazko, British Columbia, Earthquake Sequence: Injection of Magma Deep in the Crust beneath the Anahim Volcanic Belt" (2011). Geology Faculty Publications. 41. https://cedar.wwu.edu/geology_facpubs/41 
Authors

J. F. Cassidy, N. Balfour, C. Hickson, H. Kao, R. White, Jacqueline Caplan-Auerbach, S. Mazzotti, G. C. Rogers, I. Al-Khoubbi, A. L. Bird, L. Esteban, M. Kelman, J. Hutchinson, and D. McCormack 


\section{Bulletin of the Seismological Society of America}

This copy is for distribution only by

the authors of the article and their institutions in accordance with the Open Access Policy of the Seismological Society of America.

For more information see the publications section of the SSA website at www.seismosoc.org

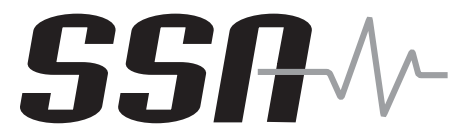

The Seismological Society of America 400 Evelyn Ave., Suite 201

Albany, CA 94706-1375

(510) 525-5474; FAX (510) 525-7204

www.seismosoc.org 


\title{
The 2007 Nazko, British Columbia, Earthquake Sequence: Injection of Magma Deep in the Crust beneath the Anahim Volcanic Belt
}

\author{
by J. F. Cassidy, N. Balfour, ${ }^{*}$ C. Hickson, ${ }^{\dagger}$ H. Kao, R. White, J. Caplan-Auerbach, \\ S. Mazzotti, G. C. Rogers, I. Al-Khoubbi, A. L. Bird, L. Esteban, ${ }^{*}$ M. Kelman, \\ J. Hutchinson, and D. McCormack
}

\begin{abstract}
On 9 October 2007, an unusual sequence of earthquakes began in central British Columbia about $20 \mathrm{~km}$ west of the Nazko cone, the most recent (circa $7200 \mathrm{yr}$ ) volcanic center in the Anahim volcanic belt. Within $25 \mathrm{hr}$, eight earthquakes of magnitude 2.3-2.9 occurred in a region where no earthquakes had previously been recorded. During the next three weeks, more than 800 microearthquakes were located (and many more detected), most at a depth of $25-31 \mathrm{~km}$ and within a radius of about $5 \mathrm{~km}$. After about two months, almost all activity ceased. The clear $P$ - and $S$-wave arrivals indicated that these were high-frequency (volcanic-tectonic) earthquakes and the $b$ value of 1.9 that we calculated is anomalous for crustal earthquakes but consistent with volcanic-related events. Analysis of receiver functions at a station immediately above the seismicity indicated a Moho near $30 \mathrm{~km}$ depth. Precise relocation of the seismicity using a double-difference method suggested a horizontal migration at the rate of about $0.5 \mathrm{~km} / \mathrm{d}$, with almost all events within the lowermost crust. Neither harmonic tremor nor long-period events were observed; however, some spasmodic bursts were recorded and determined to be colocated with the earthquake hypocenters. These observations are all very similar to a deep earthquake sequence recorded beneath Lake Tahoe, California, in 2003-2004. Based on these remarkable similarities, we interpret the Nazko sequence as an indication of an injection of magma into the lower crust beneath the Anahim volcanic belt. This magma injection fractures rock, producing high-frequency, volcanic-tectonic earthquakes and spasmodic bursts.
\end{abstract}

\section{Introduction}

The central interior of British Columbia is one of the most seismically quiescent areas of the province. In more than $40 \mathrm{yr}$ of earthquake monitoring, few earthquakes have been detected or located in the vicinity of the Nechako basin (Fig. 1). During a 25-hr period of 9-10 October 2007, eight earthquakes of $M_{\mathrm{L}}$ 2.3-2.9 occurred in the north-central part of the Nechako basin, approximately $100 \mathrm{~km}$ to the west of Quesnel (Fig. 1). Although none of these earthquakes were felt, they generated substantial local interest due to the fact that they represented a significant concentration of seismicity within the Anahim volcanic belt and within about $20 \mathrm{~km}$ of the Nazko volcanic cone. With seven temporary POLARIS (Portable Observatories for Lithospheric Analysis and

\footnotetext{
*Now at Research School of Earth Sciences, The Australian National University, Canberra ACT 0200 Australia.

'Now at Magma Energy Corp., 410-625 Howe St., Vancouver, British Columbia V6C 2 T6.

Now at CSIRO, Petroleum Resources, ARRC, 26 Dick Perry Ave., Kensington, WA 6151, Australia.
}

Research Investigating Seismicity) seismic stations and one permanent Canadian National Seismic Network (CNSN) station operating in the area (Fig. 2) at distances of 35-180 km from these initial eight earthquakes, relatively good earthquake locations (methodologies are described in the Seismic Data and Analysis section) could be determined, but focal depths could not be well-constrained. Commencing on 16 October 2007, the Geological Survey of Canada (GSC) deployed seven additional three-component broadband seismic stations in the immediate epicentral area to determine the earthquake depths and better understand the nature of this sequence. $S$ - $P$ times from the station UBRB, located directly above the earthquake swarm, clearly indicated that these were deep earthquakes $(25-35 \mathrm{~km})$. Within three weeks, more than 1000 microearthquakes occurred, most within a $5-\mathrm{km}$ radius and having magnitudes of 1 to 2 . Through November 2007, the rate of activity decreased significantly, and almost all activity ceased after about two months.

In this article we document this unusual earthquake sequence, including locations, depths, migration of seismicity, 


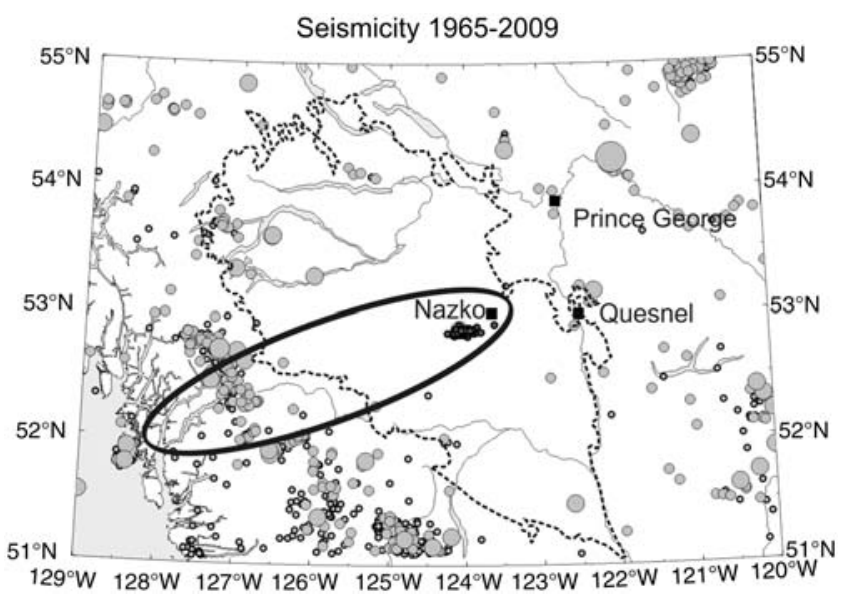

Figure 1. Seismicity of the Nechako basin (outlined by the dashed line) and adjacent areas from 1965-2009. Gray circles indicate earthquakes and are scaled by magnitude; the smallest are $M 1$, the largest is $M$ 5.4. The ellipse encircles the Anahim volcanic belt (as shown in Fig. 3). Filled squares indicate the closest communities.

and focal mechanisms, and we examine the causes and possible implications of the swarm. In this study, we only utilize data from the regional POLARIS and CNSN stations (35$180 \mathrm{~km}$ distance) as well as UBRB in the immediate epicentral region (for depth control). This allows us to avoid any station geometry and magnitude threshold biases with time and provides a consistent overview of this earthquake sequence. Analysis of data from the temporary stations deployed in the epicentral area is the focus of an ongoing study.

\section{Geology and Seismicity}

The Anahim volcanic belt is an approximately east-west trending zone of volcanic cones that stretches from the west coast of British Columbia, near Bella Bella, to the Interior plateau near Quesnel (Fig. 3). The volcanic centers include the Rainbow, Ilgachuz, and Itcha ranges, and the Nazko cone, which is the youngest at $7200 \mathrm{yr}$ old (Souther et al., 1987). There are three hypotheses for the origin of the Anahim volcanic belt: shear melting of the upper mantle due to the edge effect of a subducted oceanic plate (Madsen et al., 2006), continental rifting, and the trace of a mantle hotspot (Bevier et al., 1979). Generally, the hotspot theory is preferred (Bevier et al., 1979; Rogers, 1981; Souther et al., 1987), as the ages of the volcanoes decrease from west to east (Fig. 3), consistent with the predicted westward movement of North America at the rate of about $2.5 \mathrm{~cm} / \mathrm{yr}$. Also, there are observed chemical differences between the oldest (western) and youngest (eastern) basalts. The Nazko basalts are undersaturated alkaline lavas and are classified as basanite, suggesting a deeper source zone for magma in the Nazko area compared to the rest of the Anahim belt (Souther et al., 1987). Hickson (1987) showed that the most likely termination of the hotspot track was the Nazko area, rather than the more easterly termination suggested by Souther et al., 1987.
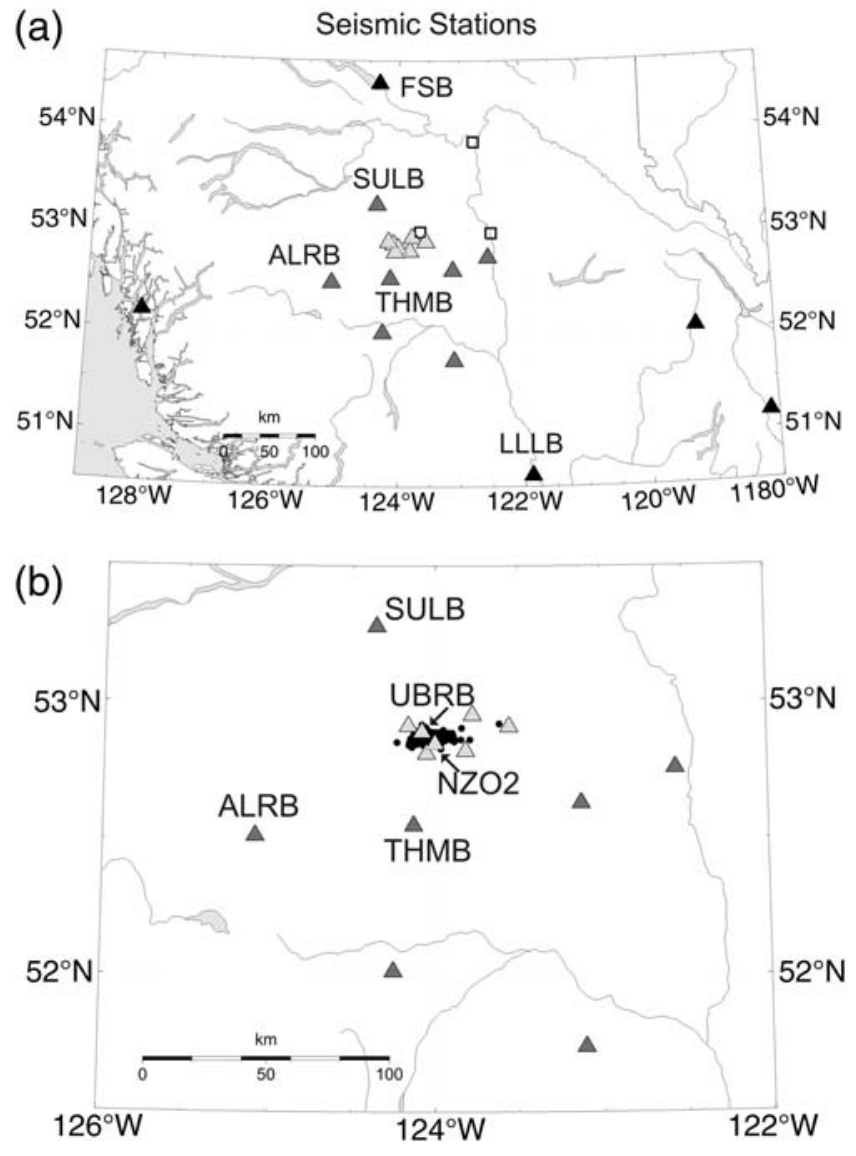

Figure 2. (a) Seismic stations in the study area include those of the CNSN, indicated by black triangles, the temporary POLARIS network (dark gray triangles), and other stations (mostly nonreal-time) temporarily deployed in the epicentral area (light gray triangles) to better monitor this earthquake swarm. Open squares indicate the closest communities. (b) Close-up of the POLARIS (dark gray triangles) and temporary (mostly non-real-time; light gray triangles) deployed in the epicentral area to better monitor this earthquake swarm (black dots). Stations discussed in the text are labeled.

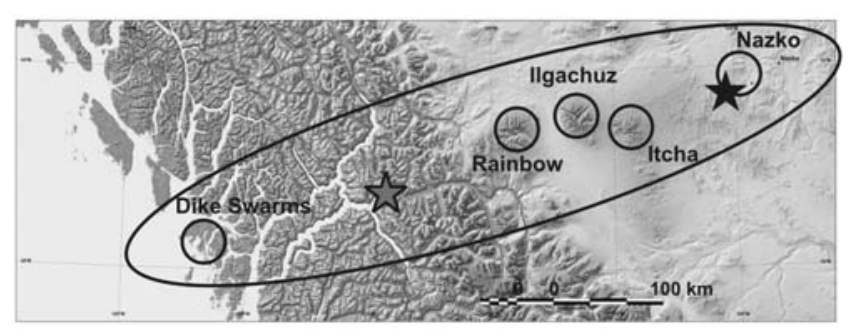

Figure 3. Topography along the Anahim volcanic belt (which lies within the ellipse). The 2007 Nazko earthquake swarm is indicated by the black star, the 1942 earthquake swarm near Bella Coola is indicated by the gray star. The large volcanic centers of the Rainbow, Ilgachuz, and Itcha volcanoes are clearly observed in the topography. The ages of the volcanics decrease from about $13 \mathrm{Ma}$ for the Dike Swarms at the western end of the belt to $8 \mathrm{Ma}$ for the Rainbow range, $5 \mathrm{Ma}$ for the Ilgachuz range, 2.5 Ma for the Itcha range, and 0.01-0.34 Ma for the Nazko cone. 
The Nechako basin is one of the most seismically quiescent areas of British Columbia. Very few earthquakes (see Fig. 1) have occurred here since 1965 when local monitoring began with a seismic station at Fort St. James (180 km to the north of Nazko). Given the seismic station distribution (Milne et al., 1978), the magnitude completeness for this general area varies from about $M 3$ in 1970 to about $M$ 1-2 in 2009. Seismicity in the area is generally concentrated within the Coast Mountains and Rocky Mountains (to the west and east, respectively, of the Nechako basin; see Fig. 1). Due to the lack of seismic stations, focal depths cannot be well-determined in this region. Within the Anahim volcanic belt, a previous earthquake swarm occurred near Bella Coola (about $200 \mathrm{~km}$ to the west of the Nazko sequence). This swarm (Fig. 3) consisted of more than 40 felt earthquakes that occurred near Bella Coola between September 1940 and August 1943 (Milne, 1956). Many of these were felt fairly strongly in Bella Coola, but none caused damage (Milne, 1956). It is assumed that these were shallow. However, due to the lack of seismic stations at this time, there is no information on focal mechanisms, magnitudes, or focal depths for these earthquakes. These events were not detected at the closest seismic station (Victoria, British Columbia) roughly $500 \mathrm{~km}$ away, so they are estimated to be less than about magnitude 4.5 .

\section{Seismic Data and Analysis}

The Nazko earthquake swarm was first detected at 03:24 UTC on 10 October 2007 (8:24 p.m. local time on 9 October), when a magnitude $\left(M_{L}\right) 2.3$ earthquake occurred in the Nechako basin (Fig. 1). Within a 25 -hr period, an unprecedented sequence of eight earthquakes ranging from magnitude 2.3 to 2.9 occurred at $52.9 \mathrm{~N}, 124.1 \mathrm{~W}$. None of these earthquakes were felt. These earthquakes were analyzed using standard GSC procedures for this region; locations were obtained using dbgenloc (Pavlis et al., 2004) and a simple layer-over-a-half-space model $\left(V_{P} / V_{S}\right.$ ratio of 1.73) that is used for the interior of British Columbia, and magnitudes were calculated using Antelope dbml (BRTT, 2010). At the time of these events, the closest seismic stations were at a distance of about $35 \mathrm{~km}$, and the magnitude threshold for earthquakes was estimated to be about $M_{L}$ 0.9. More importantly, we could not determine focal depths at this time.

Based on the similarity of waveforms (Fig. 4) and $S$ minus $P$ times, however, it was clear that these eight earthquakes were nearly colocated. Note that these earthquakes appear as typical tectonic earthquakes with relatively highfrequency content and clear $P$ and $S$ waves (Fig. 4a). Continuous waveform data were visually scanned for the month prior to these events. This revealed a few smaller events and indicated that the sequence began with a magnitude 1.5 earthquake on 9 October at 03:42 UTC (8 October at $8: 42$ p.m. local time).

Beginning on 16 October 2007, additional broadband seismographs were deployed in the immediate epicentral (a)
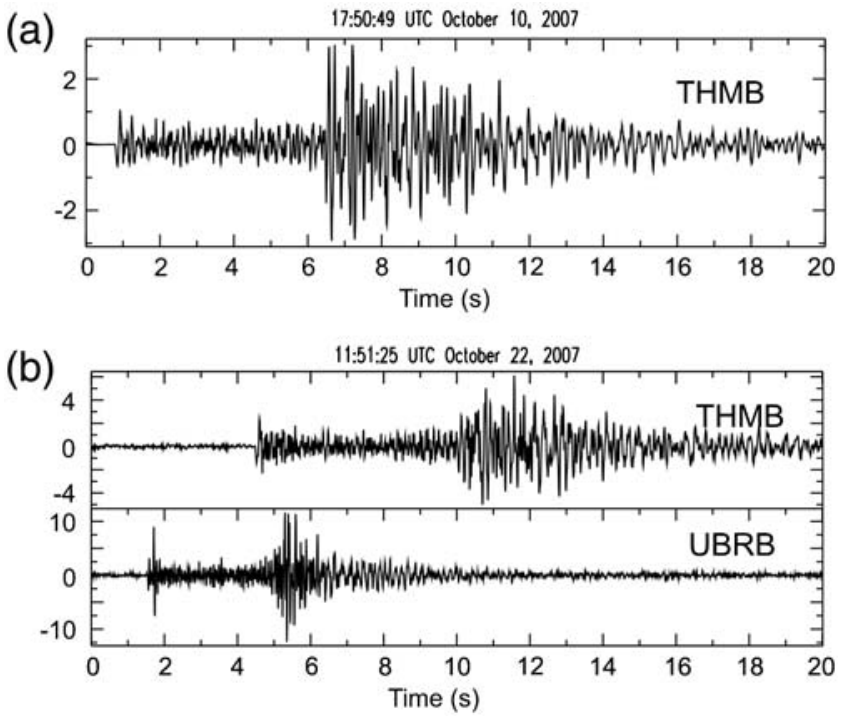

Figure 4. (a) Recording of the largest event made at station THMB (40 km from the epicenter). The waveform has been high-pass filtered at $1 \mathrm{~Hz}$. (b) Recordings of an event made at stations THMB and UBRB (directly above the earthquake swarm). The $S$ minus $P$ time at UBRB indicates that these are deep earthquakes.

region to better constrain the focal depth and provide more accurate location capability. The additional stations included three real-time Libra (Nanometrics Inc.) systems, UBRB, FPLB, MCMB, and four portable, non-real-time Taurus (Nanometrics Inc.) systems (NZ02, NZ03, NZ04, and NZ05; see Fig. 2). All seismometers were broadband: a mixture of 3 ESPs (100-s to $50-\mathrm{Hz}$ response) and 40Ts (30-s to $100-\mathrm{Hz}$ response), and all were operating at a sample rate of $100 \mathrm{~Hz}$.

The station UBRB, placed at the epicentral location of the events, has been utilized in this study (with the dbgenloc; Pavlis et al. [2004]) algorithm of Antelope (BRTT, 2010) to accurately determine focal depths. As shown in Figure 4b, although the $P$-wave arrival time at UBRB (epicentral distance near zero) is about $3 \mathrm{~s}$ earlier than at THMB (epicentral distance of about $35 \mathrm{~km}$ ), the $S-P$ time of $3.5 \mathrm{~s}$ at UBRB requires a focal depth of $25-35 \mathrm{~km}$.

Another observation from the seismograms at individual stations is that, although most waveforms were remarkably similar, there were also clear families of events with quite different waveforms. Some examples at station THMB are shown in Figure 5. Figure 5a shows a clearly compressional $P$ wave (22 October at 07:12 UTC) with diffuse (but significant) $S$-wave energy. Figure 5 b shows a clearly dilatational $P$ wave (22 October at 11:51 UTC) with a nearly identical packet of $S$-wave energy. If the $P$ wave for the 11:51 UTC event is inverted, it is nearly identical to the $P$ wave of the 07:12 event. Figure 5c shows an example of a family of events having a clear $P$ wave but little or no $S$-wave energy (1 November at 04:04 UTC). We used cross correlation to identify clusters of repeating earthquakes with correlation coefficients exceeding 0.8 with a specified master event. An example of one such cluster (at station NZ02) is shown 
(a)

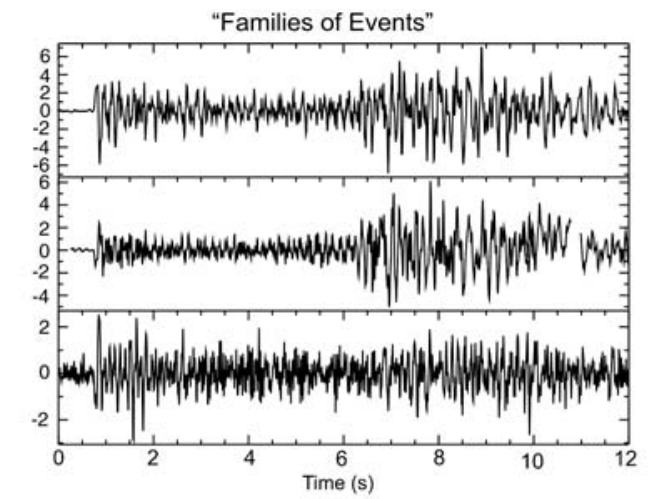

(d)

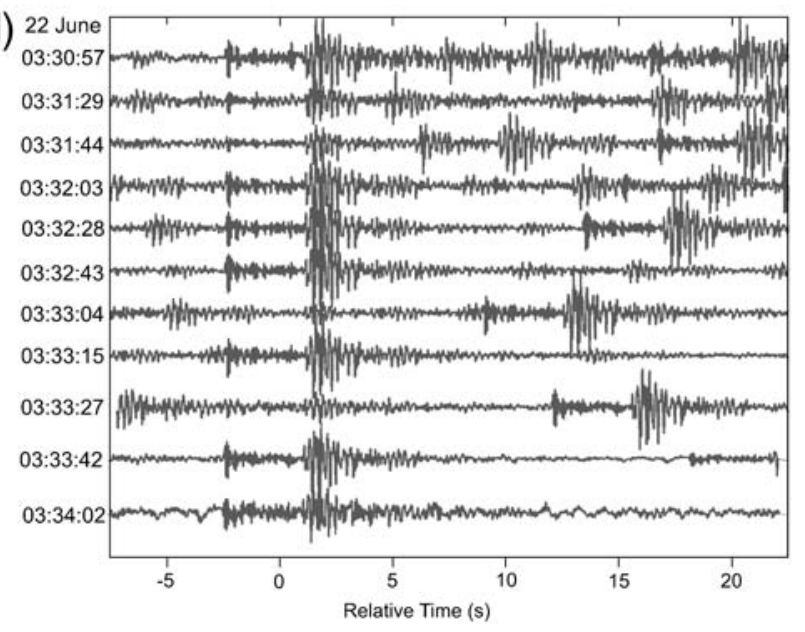

Figure 5. (a,b,c) Three distinctive families of events are shown, as recorded at the station THMB. Note the differences in first motion polarity and in the amplitude and character of the $S$ waves. (d) Cross-correlation match of waveforms at station NZ02 using a master event demonstrates the similarity of some waveforms.

in Figure 5d. Detailed analysis of data recorded at the temporary (non-real-time) stations in the epicentral area is the focus of ongoing studies (e.g., Hutchinson and CaplanAuerbach, 2010).

\section{Rate of Seismicity}

The rate of seismicity was both remarkable and strongly variable during this sequence. Figure 6 (top) shows the variation in rate of activity during a 2-hr window at station THMB on 10 October with dozens of events per hour, compared to a 2-hr window on 15 October with only a few events. Close examination of these plots reveals that each spike is an earthquake that looks like one of the events shown in Figure 5.

Of the nearly 800 events located during this sequence, 754 (or $94 \%$ of the total) occurred during the first 50 days (e.g., between 9 October and 27 November 2007). Figure 6 (bottom) shows the temporal distribution of all located events (magnitude 0.6 to 2.9, with most of $M>1.0$ ) during this 50-day window. The largest earthquakes $\left(\begin{array}{ll}M & 2.3-2.9\end{array}\right)$ all occurred on 9-10 October (days 1-2). The rate of activity (those large enough to be located) varied from a few events
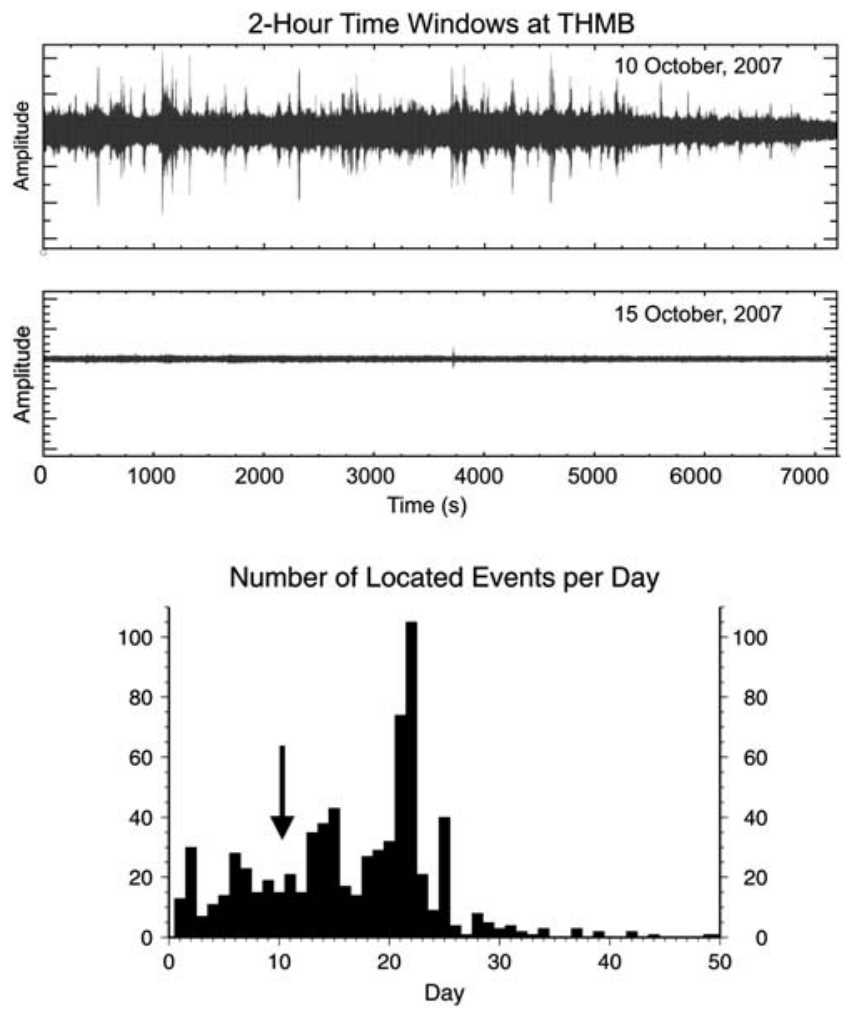

Figure 6. Top: Examples of the variation in the rate of seismic activity. These two-hour-long plots of shaking (with 1-Hz high-pass filter) recorded at THMB are plotted on the same scale. Each of the spikes is a small earthquake. Bottom: Plot of the number of events located each day (note that there were many more events too small to be located). Day 0 is 9 October 2007 and Day 50 is 27 November 2007. Peak activity occurred on 30 October. The arrow indicates that additional seismic stations were deployed for accurate depth constraints.

per day to more than 100 , with a peak in activity on day 22 (30 October). Note that all events analyzed in this study are those large enough to be located using the POLARIS and CNSN stations $(35-180 \mathrm{~km})$ and are readily identified visually at station THMB. Many additional smaller events that were recorded but not located in this study show a similar temporal pattern. It is clear that the observed seismicity pattern is not a typical mainshock-aftershock sequence with a decreasing rate of seismicity after the largest events. The thousands of tiny events that were recorded only on the temporary stations deployed in the epicentral area are the focus of ongoing research.

We utilize the maximum likelihood method (Weichert, 1980 ) to compute a $b$ value for this earthquake sequence. The data are constrained to magnitudes of about 1.4-2.9 for this swarm. This is a limited magnitude range, but we note that in volcanic zones, it is not uncommon to have a relatively small magnitude range available for $b$-value calculations (e.g., Wiemer and McNutt, 1997). The $b$ value that we compute for the Nazko sequence (Fig. 7) using the magnitude range of 1.4-2.9 is $1.9 \pm 0.2$. This is anomalous for crustal tectonic earthquakes (which typically have a $b$ value near 1.0). 


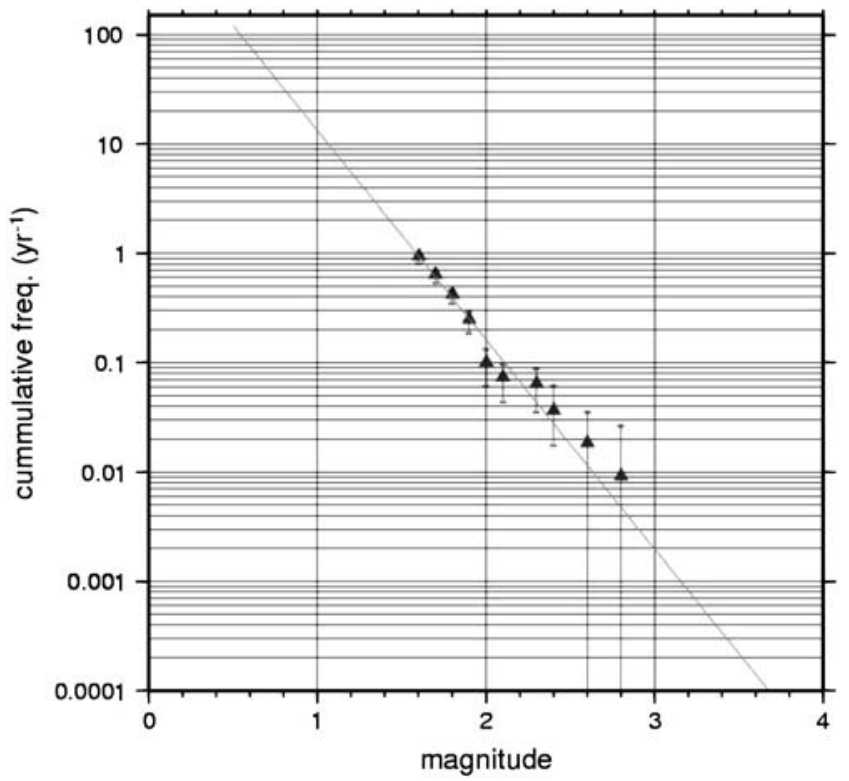

Figure 7. Plot of cumulative frequency of earthquakes (per year) as a function of magnitude for the Nazko earthquake sequence. The computed $b$ value (line) obtained using the maximum likelihood method (Weichert, 1980) is $1.9 \pm 0.2$.

However, a high $b$ value is commonly observed for earthquakes in volcanic regions (Zobin, 2003), and the value that we determine is nearly identical to the $b$ value of 2.0 observed for the 2003 Lake Tahoe deep earthquake swarm (Smith et al., 2004; von Seggern et al., 2008).

\section{Focal Mechanism}

Only one earthquake (10 October 2007 at 17:50 UTC) was large enough (e.g., had a sufficiently high signal-tonoise ratio) to determine a focal mechanism. We utilize the regional waveform inversion method (RMT) of Kao et al. (1998) to estimate the centroid moment tensor. This method has two significant advantages:

- The ability to use different velocity models for different epicenter-station pairs depending on the regional tectonic settings. For tectonically complex regions such as the volcanic belt or subduction zone, this is particularly important because the average velocity model may vary significantly with both azimuth and epicentral distance.

- The frequency band of the band-pass filter used in the waveform data processing can vary depending on the spectral ratio of signal to noise at each station. This is to maximize the constraint from each waveform, which is critical when the number of stations is sparse or when the overall signal-to-noise ratio is not optimal.

Additional details on the technical aspects of the moment tensor inversion method are provided in Kao et al. (1998).

The best-fitting solution (Fig. 8) is a normal-faulting mechanism at a depth of about $35 \mathrm{~km}$, consistent with the depth obtained from the standard earthquake location program. This RMT solution provides a reasonable fit to the observed waveforms (Fig. 8), the independently estimated depth is consistent with that from both the standard earthquake locations and the double-difference method (see the following section), and this solution is consistent with the two clear $P$-wave polarities for this event: a compressional first motion at SULB and a dilatational first motion at THMB. We note however that there must be some variation in the focal mechanisms during this swarm, as illustrated by some of the different families of events shown in Figure 5. While many recordings at THMB have a clearly dilatational first motion, others have a clearly compressional first motion (Fig. 5).

\section{Precise Relocations}

We have applied the double-difference method HypoDD (Waldhauser and Ellsworth, 2000) to obtain more precise earthquake locations. We consider only those events that were recorded after the station UBRB was deployed directly above the earthquake swarm. This provides for optimum station geometry, depth control, and a consistent dataset. A total of 5165 catalog $P$ - and $S$-wave phases recorded at seven stations from $\sim 550$ events $(M 0.6-2.0)$ were used. This equates to $\sim 268,000$ differential travel times that were used for the double-difference relocations. For the complete dataset, the least squares conjugate gradients (LSQR) mode in HypoDD was utilized. The linking parameters that were used are as follows: maximum hypocentral separation $10 \mathrm{~km}$; maximum number of neighbors per event 10 ; and minimum number of links required to define a neighbor 8 . The starting earthquake locations were the CNSN catalog locations. Two earth models were considered for the relocations, the first being a simple layer $\left(V_{P} \quad 6.2 \mathrm{~km} / \mathrm{s}\right)$ over a half-space $\left(V_{P} 8.2\right.$ and Moho at $\left.36 \mathrm{~km}\right)$ model used for standard earthquake locations in this region, and the second being a simplified version of a 1D layered model (illustrated in the Interpretation and Summary section and in Fig. 12) developed from receiver functions at station UBRB (Kim, 2010). We note that there are no significant differences in the relocation results between these two earth models. The resulting inversions indicated that only $13 \%$ of the events were weakly linked, the average number of links per pair was 6 , and the average offset between linked events was $3.9 \mathrm{~km}$ (although this was only $0.97 \mathrm{~km}$ for strongly linked events). The relocated earthquakes (Fig. 9) do not seem to show any obvious structure to the swarm; however, there is a concentration of seismicity between $26-31 \mathrm{~km}$ depth and a rather sharp termination of seismicity at about $30 \mathrm{~km}$. This coincides with the Moho interpreted from a receiver function study at this site (Kim, 2010). We tested to see if this sharp boundary was an artifact of the earth model by changing the Moho depth to $36 \mathrm{~km}$ (from $30 \mathrm{~km}$ ). The results were the same, indicating that the seismicity cut-off near $30 \mathrm{~km}$ is a robust feature of the precise relocation. 


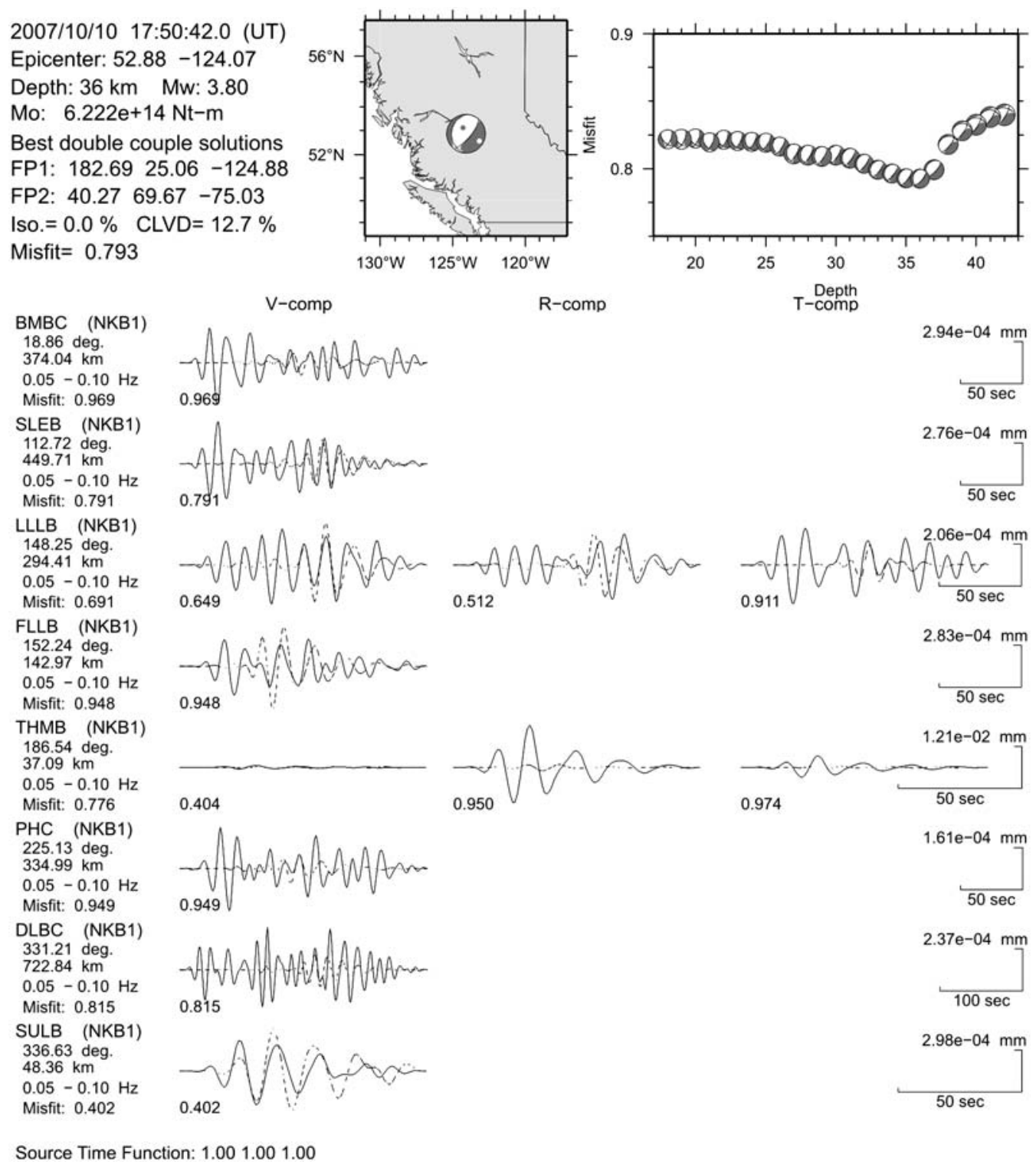

Figure 8. Regional moment-tensor solution for the largest event. Plots include the mechanism (normal faulting), observed (solid) and predicted (dashed) waveforms for the best-fit solution, and the misfit as a function of focal depth. Although not well constrained based on the large misfit value, the data indicate two things: (1) a normal faulting solution and (2) a deep (30-35 km) source.

There is a small amount of lateral migration of $\sim 0.5 \mathrm{~km} / \mathrm{d}$ to the southeast that can be seen in map view. No significant vertical migration, however, was detected using this complete dataset.

A subset of 73 events ( $M$ 0.9-2.0) was relocated using the singular value decomposition (SVD) mode in HypoDD to more accurately determine uncertainties. These 73 events included all of the "best events" or those with $P$ and $S$ waves recorded at six of the seven stations. The inversion of this subset was very well constrained, and all events were strongly linked. This test revealed uncertainties of approximately $\pm 0.3 \mathrm{~km}$ horizontally and $\pm 0.4 \mathrm{~km}$ vertically (see Fig. 10). These values are a substantial improvement compared to the estimated uncertainties of $1-3 \mathrm{~km}$ in the horizontal and 4-6 km in the vertical for single-event catalog locations. More importantly, this subset of the best events (Fig. 10) clearly shows that the migration to the southeast is real, as the event location uncertainty $(0.3-0.4 \mathrm{~km})$ is much less than the region over which the events migrated (about $4-5 \mathrm{~km})$. This subset of events suggests a slight migration to greater depths (from about $27-28 \mathrm{~km}$ at the start of the swarm to about $28-30 \mathrm{~km}$ at the end of the swarm period). Like the complete dataset, the subset shows a fairly abrupt termination of seismicity at about $30-31 \mathrm{~km}$ depth.

\section{Spasmodic Bursts}

As the earthquake swarm activity was rapidly decreasing in early November 2007 (Fig. 6), beginning on 7 November (day 30 in Fig. 6), large amplitude, high-frequency 


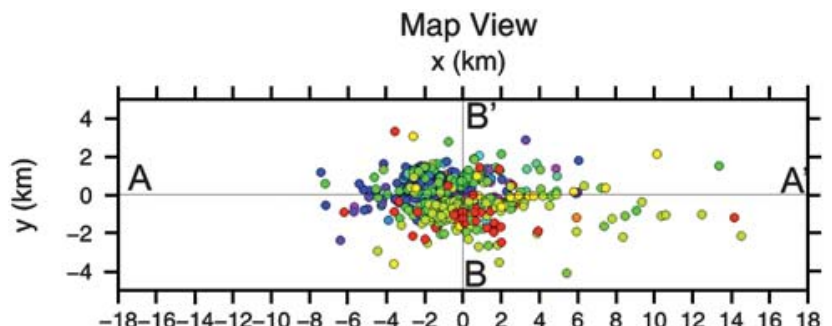

W-E Cross-Section $x(\mathrm{~km})$

$A^{\prime}$
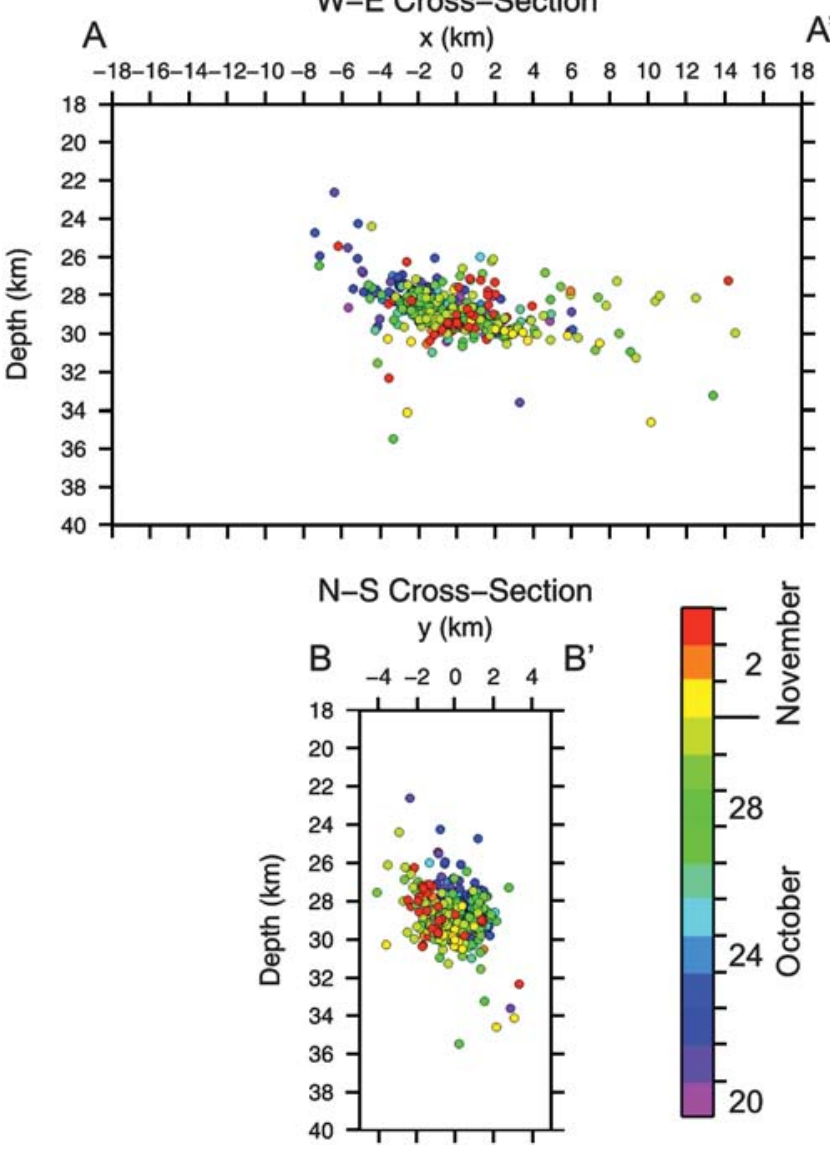

Figure 9. Double-difference relocations plotted in map view (top) and along east-west (center) and north-south cross-sections (bottom). This map includes only those events located after the station UBRB (directly above the earthquake swarm) was deployed. The locations are shaded based on time, with darker (blue-purple) colors being those early in the swarm (20-25 October) and lighter colors (red-orange) being those late in the swarm (late Octoberearly November). Note the apparent southeastward migration of $4-5 \mathrm{~km}$ and possible downward migration.

tremorlike bursts were observed across the seismic network to distances of nearly $200 \mathrm{~km}$ (see Fig. 11). Most of the energy in these bursts was at frequencies ranging from $5-15 \mathrm{~Hz}$, so they were clearly not long-period earthquakes or harmonic tremor (which generally occur prior to a volcanic eruption), but rather they were spasmodic bursts. Nonetheless, they were of concern for three reasons:

- Spasmodic bursts are generally interpreted as rock breaking that occurs just ahead of magma (Hill et al., 1990).
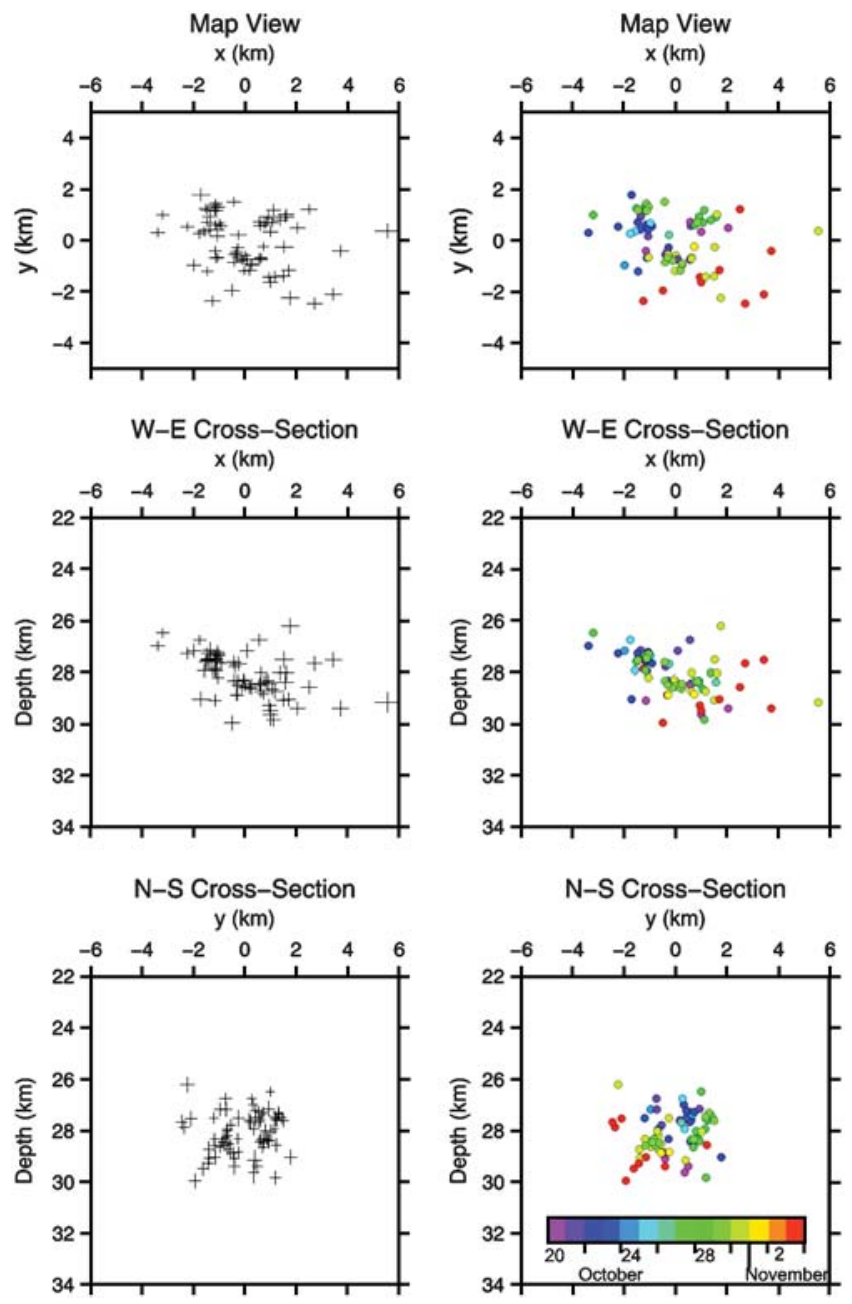

Figure 10. Double-difference relocations (using the SVD method to compute more accurate uncertainties) plotted in map view (top) and along east-west (center) and north-south (bottom) cross sections. The 73 events that comprise this subset are the best recorded events in the sequence (at 6 of 7 stations). The plots on the left show the uncertainties $(2 \sigma)$ associated with each event. The plots on the right show the same events that are color-coded based on time.

- They may be the result of water flashing to steam (if the source is at relatively shallow depths; Fournier, 1999).

- There have been volcanic eruptions in this area in the past. Although not heavily populated, the village of Nazko and forestry operations would be impacted (Hickson et al., 2009) by a modern-day eruption.

Given the possible association with magma, it was important to compute the locations, and especially the depths of the spasmodic bursts. Their emergent nature (Fig. 11) and the lack of clear $P$ waves and $S$ waves made it very difficult to locate these events using traditional earthquake-location methods. We were able to locate the spasmodic bursts using the source-scanning algorithm (SSA) of Kao and Shan (2004) that was developed to locate tremors associated with episodic tremor and slip in the Cascadia subduction zone. 

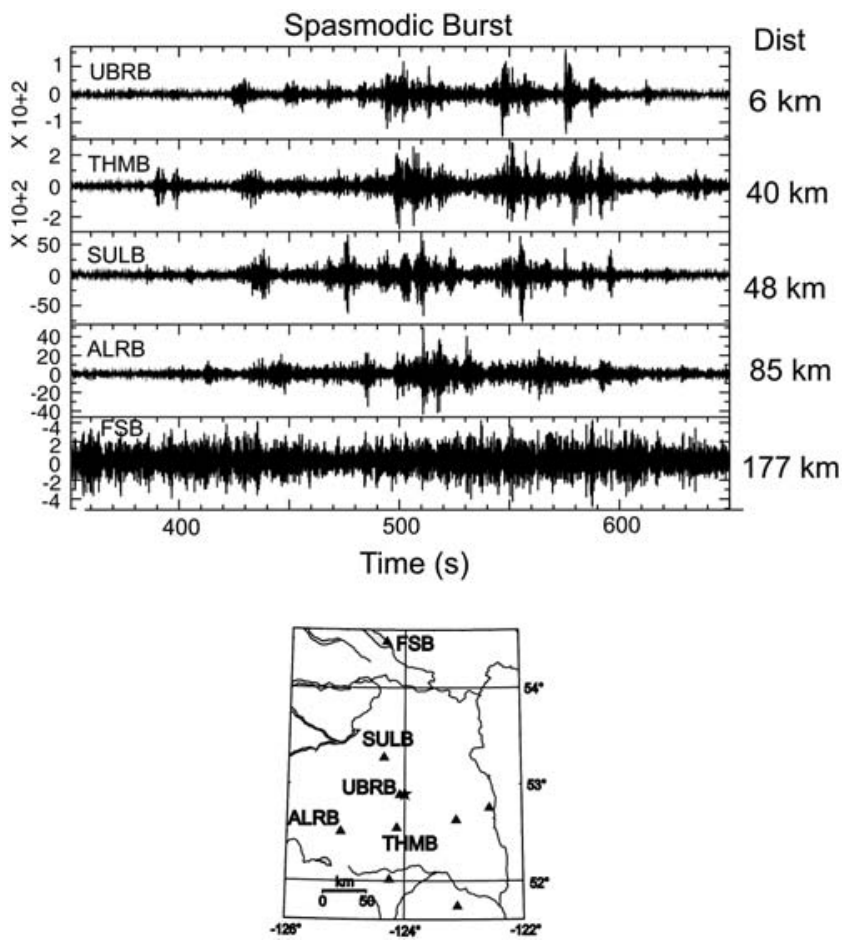

Figure 11. Spasmodic burst on 7 November, recorded across the array to distances of nearly $200 \mathrm{~km}$. Note that the distance given is epicentral distance. The source of the spasmodic burst is at $30-35 \mathrm{~km}$ depth. Station locations are shown on the map.

It is not within the scope of this study to discuss the technical details of the SSA. Therefore, only a brief summary of our SSA analysis is presented here. Basically, the SSA is a forward-searching process that scans the entire model space for seismic sources to best match the arrival of large amplitudes on the observed waveforms. For each pair of assumed origin time and hypocentral location, the absolute amplitude at the predicted arrival time is measured from each seismogram and added to the so-called brightness function. When the assumed time-location pair correctly corresponds to a real source, the brightness function will reach the maximum as large amplitudes are observed at the predicted arrival times for all stations. In other words, the true locations of seismic sources are illuminated as bright spots by the SSA.

The result of this analysis clearly indicates that the source of the spasmodic bursts is deep (30-32 km) and is essentially colocated with the earthquake swarm activity. At this depth, we were able to rule out the possibility of water flashing to steam (see discussion in the next section).

\section{Interpretation and Summary}

It is clear that these unusual earthquakes that occurred for nearly two months do not represent a typical mainshockaftershock sequence. The rate and variability of activity indicates an earthquake swarm. The well-defined depth of these earthquakes, almost all at $25-31 \mathrm{~km}$, places them in the lowermost crust. A receiver function study (Cassidy and Al-Khoubbi, 2007; Kim, 2010) at UBRB (immediately

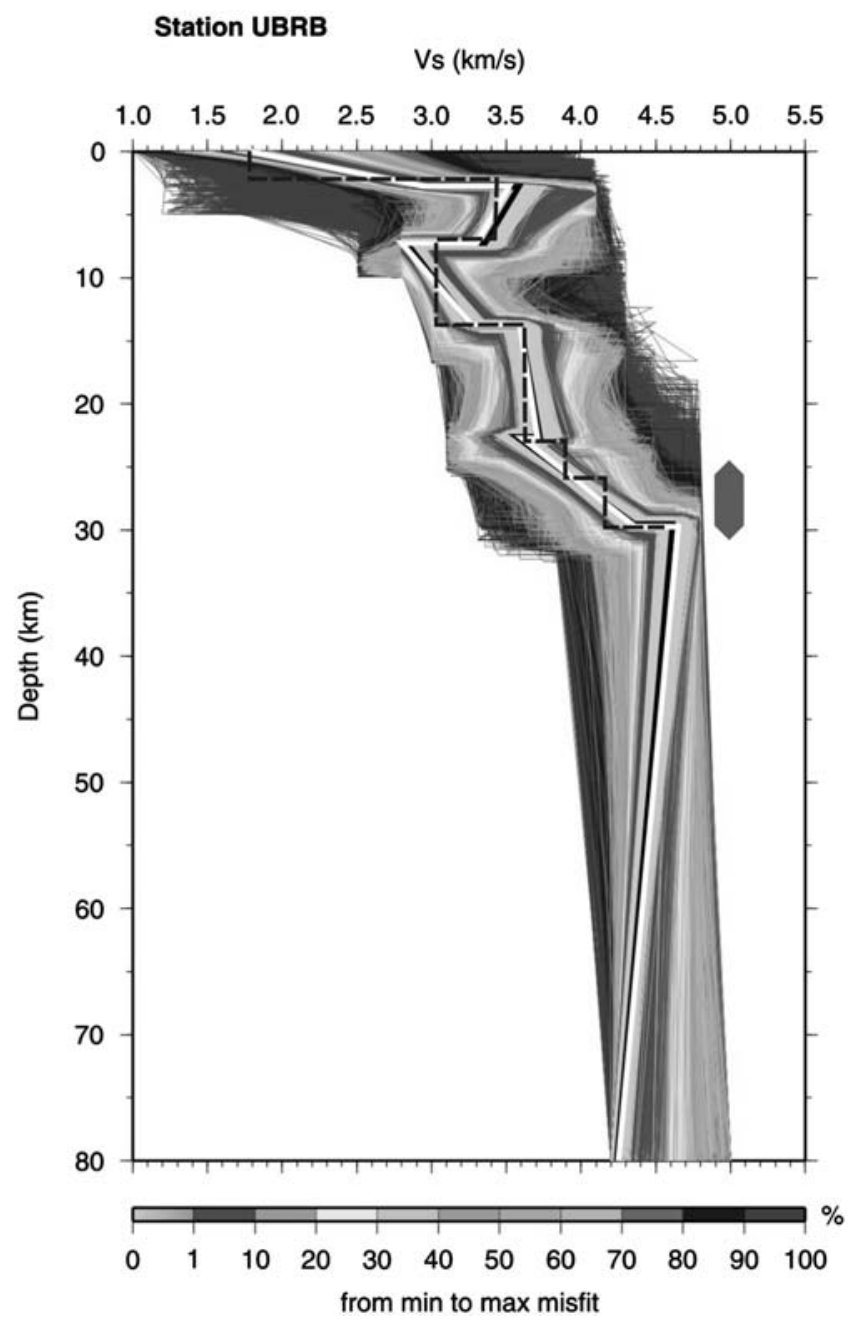

Figure 12. Plot of earth models ( $S$-wave velocity) resulting from modeling receiver function data. Of the thousands of models considered, those that provide a best fit to the observed data are plotted as the lightest colors. The model shows a Moho near $30 \mathrm{~km}$ depth, where all earthquakes (vertical bar) fall within the lowermost crust. The dashed line is a simplified version of this model used for the double-difference locations.

above the earthquake swarm) yielded a Moho depth of $30 \mathrm{~km}$ (Fig. 12). It is noteworthy that in this immediate region, there has been no known previous seismicity, and there is a very low deformation rate and relatively high temperatures (Mazzotti et al., 2008). Tectonic earthquakes are not expected in the lower crust in this region.

In a recent study, Mercier et al. (2009) imaged a lowvelocity zone in the upper mantle beneath the Nazko cone and the Anahim volcanic belt, extending down to a depth of at least $400 \mathrm{~km}$. This low-velocity zone may be indicative of a source of magma beneath the region and supports the hotspot hypothesis.

The similarities between this earthquake swarm and the 2003 Lake Tahoe swarm (Smith et al., 2004) are remarkable. For both the Lake Tahoe swarm and the Nazko swarm, the following is true: 
- Deep earthquakes occurred in a relatively aseismic area: for Lake Tahoe, no deep crustal earthquakes had been observed in $25 \mathrm{yr}$ of monitoring, and for the Nazko area, no deep crustal earthquakes had been seen in more than $45 \mathrm{yr}$ of monitoring.

- All earthquakes were small $\left(M_{\mathrm{L}}<3\right)$.

- All earthquakes were confined to the lower crust (25-33 km).

- The daily number of earthquakes varied drastically during the swarm, from only a few events per day to approximately 100 earthquakes per day.

- The $b$ value determined was $\sim 2$, which is anomalous for crustal tectonic earthquakes.

- Earthquakes migrated during the sequence at rates of approximately $0.2 \mathrm{~km} / \mathrm{d}$ (Tahoe) and $0.5 \mathrm{~km} / \mathrm{d}$ (Nazko).

- The rupture zone covered an elliptical area of approximately 60-100 square kilometers.

One dataset lacking in the region of the Nazko swarm is measurements of crustal deformation. There were no GPS instruments in the region and thus no estimates of deformation to compare with motions observed during the Lake Tahoe sequence.

Based on the striking seismic similarities with the Tahoe swarm, the observation of deep crustal earthquakes in a region where tectonic earthquakes are not expected, the observation of colocated spasmodic bursts, and the indications of lower crustal and upper mantle low-velocity zones (from recent earth structure studies in this area) that support the presence of magma, we interpret this earthquake swarm as resulting from a magma injection into the lower crust beneath the Nechako basin. Most magma injection or emplacement into the crust is in a tensile regime, consistent with the focal mechanism we calculated for the largest earthquake in the sequence. We note, however, that there is very limited information on the stress regime at Nazko at this time.

The Nazko earthquake swarm appears to be over; during the $3 \mathrm{yr}$ since the swarm began (which peaked on 30 October 2007), only 10 small events occurred during December 2007 , and 14 events were recorded during the first 5 months of 2008. No events have been recorded (as of December 2010) since 15 May 2008. This earthquake swarm is not likely indicative of near-future volcanism in the Anahim volcanic belt (at Nazko cone or elsewhere), but rather is likely a glimpse into the evolutionary process that contributes to crustal growth via injection of magma into the lowermost crust of the earth.

\section{Data and Resources}

Seismic data used in this study were collected as a part of the POLARIS project and the Canadian National Seismograph Network (CNSN) and are available at http:// earthquakescanada.nrcan.gc.ca/stndon/index-eng.php (last accessed September 2010). Antelope (BRTT, 2010) was used to process the data, and earthquakes were located using genloc (Pavlis et al., 2004) and HypoDD (Waldhauser and Ellsworth, 2000).

Some plots were made using the Generic Mapping Tools version 4.2.1 (www.soest.hawaii.edu/gmt; Wessel and Smith, 1998).

\section{Acknowledgments}

We gratefully acknowledge the many people who contributed to this study. Special thanks to Isa Asudeh, Andy Tran, Mingzhou Li, Calvin Andrews, Richard Baldwin, Wanda Bentkowski, Tim Cote, Khalil Hayek, Chris Majewski, Xiuying Jin, Tim Claydon, Kelly Russell, Graham Andrews, Bob Tilling, Don Swanson, Robert Kung, Kaz Shimamura, Barry Narod (MT), Terry Spurgeon, Glyn Williams-Jones, the Ottawa infrasound group, Fish Pot Lake Lodge, Brian Wear, British Columbia Provincial Emergency Preparedness members and residents of the Community of Nazko. Seismic data analyzed in this study came from the CNSN (funded by Natural Resources Canada) and the Nechako POLARIS array (funded by Geoscience British Columbia, Natural Resources Canada, and the British Columbia Ministry of Energy, Mines, and Petroleum Resources). N. Balfour was supported by an NSERC Discovery grant. We gratefully acknowledge three reviewers for their very valuable suggestions and contributions that improved this manuscript. This is ESS Contribution Number 20090362.

\section{References}

Bevier, M. L., R. L. Armstrong, and J. C. Souther (1979). Miocene peralkaline volcanism in west-central British Columbia-its temporal and plate-tectonics setting, Geology 7, 389-392.

BRTT (2010). Boulder Real Time Technologies. http://www.brtt.com, last accessed 28 December 2010.

Cassidy, J., and I. Al-Khoubbi (2007). A passive seismic investigation of the geological structure within the Nechako Basin, In The Nechako Initiative-Geoscience Update 2007 British Columbia Ministry of Energy, Mines and Petroleum Resources, Petroleum Geology Open File 2007-1, 1-6.

Fournier, R. O. (1999). Hydrothermal processes related to movement of fluid from plastic into brittle rock in the magmatic-epithermal environment, Bull. Soc. Econ. Geol. 94, 1193-1212.

Hickson, C. J. (1987). Quaternary volcanism in the Wells GrayClearwater area, east central British Columbia; Ph.D. Thesis, University of British Columbia, $357 \mathrm{pp}$.

Hickson, C. J., M. C. Kelman, W. Chow, K. Shimamura, R. Servranckx, D. Bensimon, J. F. Cassidy, S. Trudel, and G. William-Jones (2009). Nazko region volcanic hazard map, Geological Survey of Canada, Open File 5978, 1 sheet.

Hill, D. P., W. L. Ellsworth, M. J. S. Johnston, J. O. Langbein, D. H. Oppenheimer, A. M. Pitt, P. A. Reasenberg, M. L. Sorey, and S. R. Mcnutt (1990). The 1989 earthquake swarm beneath Mammoth Mountain, California: An initial look at the 4 May through 30 September activity, Bull. Seismol. Soc. Am. 80, 325-339.

Hutchinson, J., and J. Caplan-Auerbach (2010). New perspectives on the 2007 seismic swarm in the Anahim Volcanic Belt, British Columbia, from earthquake cross-correlation and high-resolution relocations, Abstract S21B-2039 presented at 2010 Fall Meeting, AGU, San Francisco, Calif., 13-17 December.

Kao, H., P.-R. Jian, K.-F. Ma, B.-S. Huang, and C.-C. Liu (1998). Momenttensor inversion for offshore earthquakes east of Taiwan and their implications to regional collision, Geophys. Res. Lett. 25, 3619-3622.

Kao, H., and S.-J. Shan (2004). The Source-Scanning Algorithm: Mapping the distribution of seismic sources in time and space, Geophys. J. Int. 157, 589-594.

Kim, H.-S. (2010). Mapping crustal structure of the Nechako Basin using teleseismic receiver functions, M.Sc. Thesis, University of Victoria, $121 \mathrm{pp}$. 
Madsen, J. K., D. J. Thorkelson, R. M. Friedman, and D. D. Marshall (2006). Cenozoic to recent plate configurations in the Pacific Basin: Ridge subduction and slab window magmatism in western North America, Geosphere 2, no. 1, 11-34; doi 10.1130/GES00020.1.

Mazzotti, S., L. J. Leonard, R. D. Hyndman, and J. F. Cassidy (2008). Tectonics, dynamics, and seismic hazard in the Canada-Alaska Cordillera, In J. T. Freymueller, P. J. Haeussler, R. L. Wesson, and G. Ekstrom (Editors), Active Tectonics and Seismic Potential of Alaska, Geophys. Monograph Series 179, 297-319, Amer. Geophys. Union.

Mercier, J.-P., M. G. Bostock, J. F. Cassidy, K. Dueker, J. B. Gaherty, E. J. Garnero, J. Revenaugh, and G. Zandt (2009). Body-wave tomography of western Canada, Tectonophys. 475, no. 3-4, doi 10.1016/j.tecto.2009.05.030.

Milne, W. G. (1956). Seismic activity in Canada west of the $113^{\circ}$ meridian, 1841-1951, Publications of the Dominion Observatory, Ottawa, 18, $119-145$.

Milne, W. G., G. C. Rogers, R. P. Riddihough, G. A. McMechan, and R. D. Hyndman (1978). Seismicity of Western Canada, Can. J. Earth Sci. 7, 1-11.

Pavlis, G. L., F. Vernon, D. Harvey, and D. Quinlan (2004). The generalized earthquake-location (GENLOC) package: An earthquake-location library, Comput. Geosci. 30, no. 9-10, 1079-1091, ISSN 00983004, doi 10.1016/j.cageo.2004.06.010.

Rogers, G. C. (1981). McNaughton Lake seismicity-More evidence for an Anahim hotspot?, Can. J. Earth Sci. 18, 826-828.

Smith, K. D., D. Von Seggern, G. Blewitt, L. Preston, J. G. Anderson, B. P. Wernicke, and J. L. Davis (2004). Evidence for deep magma injection beneath Lake Tahoe, Nevada-California, Science 305, 1277-1280, doi 10.1126/science.1101304.

Souther, J. G., J. J. Clague, and R. W. Mathewes (1987). Nazko Cone: A Quaternary volcano in the eastern Anahim Belt, Can. J. Earth Sci., 24, 2477-2485.

von Seggern, D., K. D. Smith, and L. A. Preston (2008). Seismic spatialtemporal character and effects of a deep (25-30 km) magma intrusion below North Lake Tahoe, California-Nevada, Bull. Seismol. Soc. Am. 98, 1508-1526.

Waldhauser, F., and W. Ellsworth (2000). A double-difference earthquake location algorithm: Method and application to the northern Hayward Fault, California, Bull. Seismol. Soc. Am. 90, 1353-1363.

Weichert, D. H. (1980). Estimation of the earthquake recurrence parameters for unequal observation periods for different magnitudes, Bull. Seismol. Soc. Am. 70, 1337-1346.

Wessel, P., and W. H. F. Smith (1998). New, improved version of the Generic Mapping Tools released, Eos Trans. AGU 79, 579.

Wiemer, S., and S. R. McNutt (1997). Variations in the frequency-magnitude distribution with depth in two volcanic areas: Mount St. Helens,
Washington, and Mt. Spurr, Alaska, Geophys. Res. Lett. 24, no. 2, $189-192$

Zobin, V. (2003). Introduction to Volcanic Seismology, Elsevier Science, Amsterdam, Netherlands, 290 pp.

Geological Survey of Canada

9860 West Saanich Road

Victoria, British Columbia V8L 4B2

jcassidy@nrcan.gc.ca

(J.F.C., H.K., S.M., G.C.R., I.A., A.L.B., L.E.)

School of Earth and Ocean Sciences

Bob Wright Centre A405

University of Victoria

PO Box 3065 STN CSC

Victoria, British Columbia V8W 3V6

(N.B.)

Geological Survey of Canada

625 Robson St., 14th floor

Vancouver, British Columbia V6B 5J3

(C.H., M.K.)

Volcano Disaster Assistance Program

U.S. Geological Survey and OFDA

345 Middlefield Rd, Mail Stop 910

Menlo Park, California 94025

(R.W.)

Western Washington University

Geology Department, 516 High St.

MS 9080

Bellingham, Washington 98225

(J.C., J.H.)

Geological Survey of Canada

7 Observatory $\mathrm{Cr}$.

Ottawa

Ontario K1A $0 \mathrm{Y3}$

(D.M.)

Manuscript received 12 January 2010 